\title{
Additive Manufacturing and Supply Chain Configuration: Modelling and Performance Evaluation
}

\author{
Marta Rinaldi (D), Mario Caterino iD, Roberto Macchiaroli iD \\ University of Campania "Luigi Vanvitelli" (Italy) \\ marta.rinaldi@unicampania.it,mario.caterino@unicampania.it, roberto.macchiaroli@unicampania.it
}

Received: May 2021

Accepted: November 2021

\begin{abstract}
:
Purpose: the aim of the study is to compare the performance of different supply chain configurations adopting Additive Manufacturing. Five input factors have been varied with the aim of testing the response of the supply chain to different starting conditions. In order to evaluate the supply chain performance, a set of key performance indicators have been identified considering both manufacturing and logistic processes.
\end{abstract}

Design/methodology/approach: A discrete event simulation model has been developed in order to reproduce the behavior of the players according to their role in the supply chain. Different supply chain configurations have been modelled to assess the performance of the solution combined with different input factors. Many scenarios have been tested with the aim of identifying suitable applications of the additive technology.

Findings: in general, the decentralized configuration has better logistic performance than the centralized supply chain. In fact, it is more flexible, suitable for high service levels, and less affected by the variability of the demand. However, when the distances among players are very short and the average demand is low, the benefits in adopting a decentralized configuration are very limited.

Concerning the performance of the production phase, the centralized structure allows providing a better capacity utilization, exploiting the potential of a High-cost machine with higher production camera volume and speed.

Practical implications: the outcomes obtained allow deriving some useful guidelines, which could help practitioners to identify a suitable application of the additive technology.

Originality/value: first, the model provides a quantitative evaluation. Moreover, the study analyzes the performance of the additive technology combined with different supply chain configurations. This is a strong point since it is well known that emerging manufacturing technologies can affect the structure and the performance of the whole supply chain.

Keywords: additive manufacturing, supply chain modelling, discrete event simulation, supply chain structure

\section{To cite this article:}

Rinaldi, M., Caterino, M., \& Macchiaroli, R. (2022). Additive manufacturing and supply chain configuration: Modelling and performance evaluation. Journal of Industrial Engineering and Management, 15(1), 103-123. https://doi.org/10.3926/jiem.3590 


\section{Introduction}

Additive Manufacturing (AM) is a production technology, which completely differs from the traditional subtractive approach. AM allows creating objects joining material layer by layer rather than removing material from a block or through molding technologies. The AM production phase just needs digital 3D data of the product and specific tools can be avoided as well as final assembly stages. Since it is totally opposite to the conventional subtractive technologies, it has the potential to change the way of producing and delivering products (Verboeket \& Krikke, 2019). Jiang, Kleer and Piller (2017) have estimated that in 2030, the $50 \%$ of the overall industrial AM capacity will be in-house production capacity, and the distribution of final products will move significantly from selling the physical product to selling digital files for direct manufacturing.

In the last decades, AM has become a highly discussed topic and many researchers have started to study its benefits as alternative production strategy compared to traditional manufacturing (Attaran, 2017). Well-known advantages include environmental considerations, and AM has demonstrated to have a green potential compared to the subtractive methods (Rejeski, Zhao \& Huang, 2018). In the recent years, the impact of AM on supply chain (SC) performance has started to be investigated (Oettmeier \& Hofmann, 2016). In general, AM seems to offer many benefits to industries, but it also has a significant impact on supply chain processes, organization and relations among stakeholders. A crucial point is the custom design and the possibility to offer quick and flexible response to the market with small and economical batches (Achillas, Aidonis, Iakovou, Thymianidis \& Tzetzis, 2015). In fact, AM promotes a rapid design of the product, changing the relation with the customer and creating dynamic connections (Dwivedi, Srivastava \& Srivastava, 2017). At the same time, a strong collaboration with suppliers is required since the characteristics and quality of raw material are fundamental for the printing process (Wang, Blache \& Xu, 2017). Moreover, by producing a single body, the AM limits the number of components, drastically reducing the number of suppliers (Nyamekye, Leino, Piili \& Salminen, 2015). The combination of such factors also has a positive effect on the inventory management with a stock level reduction in both raw material and final product (Ghadge, Karantoni, Chaudhuri \& Srinivasan, 2018). In fact, one of the main potential effect of additive production is the possibility to make supply chains less complex and logistics more efficient. There is evidence that the faster production process combined with the simpler supply network reduces the supply chain lead time (SCLT). It has been estimated a SCLT reduction up to $60 \%$ switching from conventional to additive manufacturing (Huang, Riddle, Graziano, Das, Nimbalkar, Cresko et al., 2017). Finally, since AM technology allows decentralized manufacturing, it reduces the delivery time, the distance and the transportation costs.

Despite the widely discussed benefits of AM on SC performance, SC reconfiguration due to a new production approach has received less attention (Tziantopoulos, Tsolakis, Vlachos \& Tsironis, 2019). Additive Manufacturing implicates a new manufacturing concept, involving the customer in the product design and promoting home fabrication (Rogers, Baricz \& Pawar, 2016). Indeed, the right way to take the best advantages from such technology is to move to a distributed production with small and flexible facilities located close to the customers. For such reason, AM is considered a potential disruptive technology for supply chains, because it could completely revise or even create new configurations. However, few studies measure the impact of AM on supply chains by focusing on supply chain reconfiguration (Zhang, Jedeck, Yang \& Bai, 2019).

Starting from the considerations above, this paper aims to contribute to the current literature with a quantitative evaluation of the impact of Additive Manufacturing on the Supply chain performance. In particular, the response of different supply chains with different structure have been studied. A discrete event simulation model has been developed in order to reproduce the behavior of the players according to their role and position in the network. Different supply chain configurations have been tested to assess the SC response considering different SC structures. Moreover, many scenarios have been reproduced with the aim of identifying the best application considering different starting conditions. To this purpose, five different input factors have been varied in order to test the key factors, which could influence the design of the SC structure. In order to evaluate the SC performance, a set of key performance indicators (KPI) have been identified focusing on both manufacturing and logistic processes. 
The remainder of the paper is structured as follows. Section 2 reviews the current literature focusing on researches which study the additive manufacturing adoption and its impact on the supply chain reconfiguration. The simulation model is presented in Section 3, which details the main logics, assumptions and formulations. Section 4 introduces the numerical example and explains the plan of experiments, and Section 5 deals with the numerical results. Finally, the last section summarizes the main findings of the study and the future research directions.

\section{Literature Analysis}

In recent years, the impact of additive manufacturing on supply chain performance have started to be investigated. However, its potential disruptive effect on existing supply networks has not been deeply discussed. A number of researchers have debated the implications of AM on supply chain structure with conceptual or qualitative studies. Several researchers have reviewed the literature dealing with the impact of additive manufacturing on supply chain organization. Franco, Ganga, de Santa-Eulalia and Godinho-Filho (2020) have explored the current literature focusing on the effect of additive adoption on operations and supply chain management. As a conclusion, they opened a number of opportunities for future researchers including quantitative studies on supply chain complexity and flexibility. Kunovjanek, Knofius and Reiner (2020) have discussed on the perceived benefits and the possible applications to different sectors, fixing an interesting point for future studies: researchers have moved to propose solutions based on decentralization and in-house production, but a trade-off between investment and opportunities has to be found. Ryan, Eyers, Potter, Purvis and Gosling (2017) have considered the concept of the geographic distribution of manufacturing as key driver for defining the supply chain network. In fact, the choice of the structure of a supply chain should be linked to the geographical coverage provided by each node (Storper \& Harrison, 1991). Some studies have focused on qualitative evaluations or empirical analysis. In 2010, Holmström, Partanen, Tuomi and Walter (2010) have compared two supply chain configurations (centralized and decentralized) with the aim of studying the adoption of additive manufacturing and describing potential benefits. Some considerations in terms of production costs, inventory costs and investment costs for machines have been presented. Sasson and Johnson (2016) have introduced an alternative scenario where additive and traditional production coexist and they presented the potential changes in the supply chain configuration. They discussed the possible response of different systems focusing on the volume and the variability of the demand. Öberg (2019) has investigated the consequences of AM implementation on supply chains considering the position of different players on the system and evaluating the different points of view. An empirical analysis has been conducted to understand how the players perceive the changes due to $\mathrm{AM}$, and the actions implemented to maintain and defend their positions in the system.

Some studies have modelled and measured the disruptive effect of AM on supply chains, proposing quantitative evaluations. Liu, Huang, Mokasdar, Zhou and Hou (2014) have studied the performance of a conventional aircraft spare parts supply chain against a system based on AM technology with centralized and decentralized structure. They showed the potential of AM in changing the traditional configuration focusing on logistics and inventory management. Barz, Buer and Haasis (2016) have performed a computational study in order to analyze the impact of AM on the supply network structure; three different networks have been proposed, and transport and facility costs have been computed to compare them. The study shows a good improvement by moving the production sites closer to the customers. Different configurations have been modelled by Khajavi, Partanen and Holmström (2014) considering centralized and distributed production scenarios; a cost analysis has been conducted offering a cost trade-off and providing some guidelines on AM machines and technology development. Li, Jia, Cheng and Hu (2017) compared three supply chain scenarios and a conventional spare parts SC vs. two configurations adopting additive have been simulated. All the solutions have been modelled differing from each other in terms of configuration and transportation process. Results showed that the AM structure allows joining the manufacturing and distribution phase in one step reducing transportation costs and carbon emissions.

More recently, Rinaldi, Caterino, Fera, Manco and Macchiaroli (2021) have introduced a green approach for technology selection based on the supply chain configuration. Additive and Traditional manufacturing have been compared testing different supply networks and using a set of economic and environmental metrics. Roca, 
Vaishnav, Laureijs, Mendonça and Fuchs (2019) have presented an optimization model in order to identify the location and the number of production facilities considering production and logistic costs. Different scenarios have been tested considering a potential improvement in the additive technology in terms of machine cost, productivity and quality of the final product. Chowdhury, Shahvari, Marufuzzaman, Francis and Bian (2019) have proposed an optimization model investigating the impact of significant factors on the design and management of an AM supply network. They joined long-term investment decisions (e.g., facility location selection) and short-term operational decisions (e.g., transportation and storage capacity decisions) with the aim of determining a suitable structure of the network. A simulation study has been proposed by $\mathrm{Li}$, Cheng, Hu, Zhou, Ma and Lim (2019) with the aim of identifying a configuration for an AM-based spare parts supply chain with heterogeneous demand. Both centralized and distributed structure have been modelled changing the locations of machines and moving them closer to the customers. Finally, a mixed scenario has been analyzed with the aim to make the best use of both configurations.

This paper contributes to the current literature evaluating the performance of different supply chain configurations adopting Additive Manufacturing. In particular, both manufacturing and logistic processes have been considered, and the response of the supply chain to different starting conditions has been measured.

\section{Simulation Model}

\subsection{Supply Chain Configuration}

The current literature has demonstrated that technological changes and innovations could strongly influence the SC performance and structure (Ivanov, Dolgui \& Sokolov, 2019). As already discussed in the previous section, Additive Manufacturing is a new technology, which completely differs from the traditional subtractive approach. Its application may cause strong changes within supply chains and it may affect the relationship between SC players. Thanks to the simulation tool, this paper evaluates the SC performance testing different scenarios with simple and fast changes. Two different AM configurations have been reproduced in order to study the feasibility of AM in different SC environments. In particular, the supply chain structures have been defined considering the disruptive role assigned to the technology by the current literature (Mohr \& Khan, 2015). Thus, two supply chain configurations have been modelled: a traditional centralized Supply Chain, where the manufacturing process is managed by a limited number of plants and a decentralized Supply Chain, where the production is distributed among many local facilities.

The first configuration is presented in Figure 1, which shows the flow of materials between the supply chain levels. A four-echelon network has been modelled to reproduce the behavior of a centralized production system. A single supplier has been introduced only considering the procurement of the main raw material. Moreover, since the characteristics of the powder strongly affect the additive process, the producers usually collaborate with the suppliers of the AM equipment, who also provide the raw materials (Pour, Zanardini, Bacchetti \& Zanoni, 2016). For such reasons, the manufacturer generally exploits only one supplier with a single sourcing approach. The manufacturing process is performed by two different Original Equipment Manufacturers (OEM), who handle and control the whole phase. The choice of inserting two different producers instead of one derives from some considerations: mass production and economies of scale are affected by the machine productivity and AM is less competitive than traditional manufacturing with high production volumes (Baumers, Dickens, Tuck \& Hague, 2016). Instead, additive technology may replace subtractive manufacturing for small and medium production volumes (Atzeni \& Salmi, 2012). Therefore, two OEMs have been modelled to reduce the production volume and reproduce a system close to the real-life; in this way, the choice becomes coherent with the real use of the technology. Once the production stage has been concluded, the distribution of the final product is performed by eight different local distribution centers (LDC), who directly face the final customer.

Starting from the first modelling, the second configuration has been designed (Figure 2). Since AM technology well fits for small batches and promotes home fabrication (Rayna \& Striukova, 2016), the second AM scenario adopts a highly decentralized structure. The manufacturing phase has been moved to the local level and a final network composed of three echelon has been modelled. In such case, the eight local centers become independent producers equipped to manage and control their proper production. The manufacturing stage is split and located close to the 
final customer. Each OEM deals with both the production and distribution phase, allowing to design a shorter supply chain to reduce the complexity of the whole network. In fact, the physical distribution stage is basically bypassed and joined with the production one.

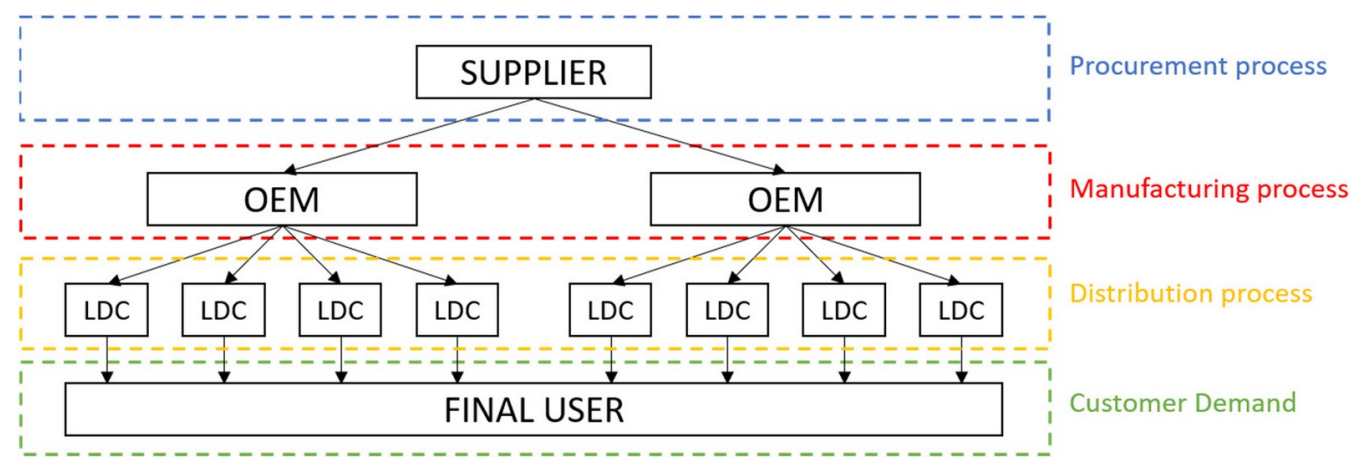

Figure 1. Supply chain configuration - Centralized Supply Chain

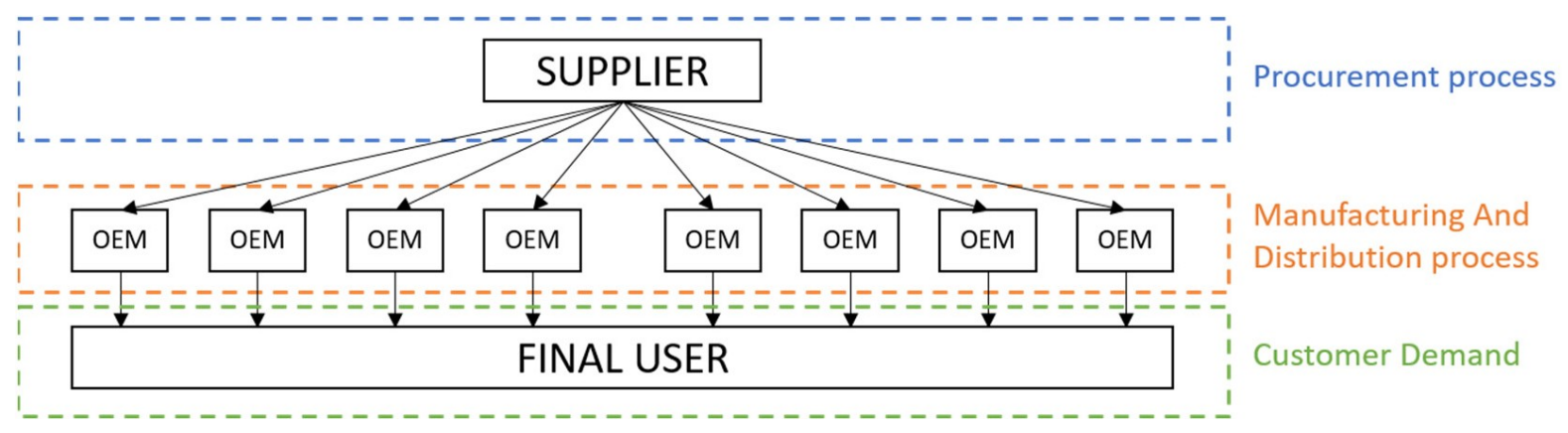

Figure 2. Supply chain configuration - Decentralized Supply Chain

\subsection{Model Formulation}

A discrete event simulation model has been designed using the computational potential of Microsoft Excel ${ }^{\mathrm{TM}}$. The two configurations have been modelled separately according to their specifications; however, similar production and distribution behaviors have been implemented in order to compare the performance of the two systems. One year (240 days) has been simulated with a time step of 1 day. Table 1 presents the notations used to describe the model formulation.

The different SC players have been modelled considering their role in the network. In particular, specific inventory policies and production rules have been implemented in the simulation model in order to reproduce the behavior of each SC level. A homogenous production has been investigated, considering the production of a single product.

The structure of the simulator is presented in Figure 3. For both the configurations, the input data for the simulation is the customer demand, which has been modelled as a normal distribution with $\left(\mu_{d}, \sigma_{d}\right)$. Then, the simulation splits into two different branches, following the two different supply chain structures. In particular, starting from the Centralized Supply Chain, the final customer faces the LDC, which in turn faces the OEM (right branch); instead, in the Decentralized Supply Chain, the final customer directly faces the OEM (left branch). The OEM production strategy and the logics implemented to simulate the behavior of the supplier are common for both the configurations. The decision process of each SC level and the logics implemented in the simulation model are detailed below..

The supplier is the first player, upstream in the supply chain. He manages the procurement process and provides the powders to the OEMs. As already explained, just one raw material and a single sourcing strategy has been considered. A simple procurement logic has been implemented, considering one delivery at the beginning of the week with the right amount required for the weekly production. 


\begin{tabular}{|c|c|c|c|}
\hline Indices & & & \\
\hline$t$ & Day & & \\
\hline$w$ & Week & & \\
\hline$m$ & Month & & \\
\hline $\mathrm{R} M$ & Raw material & & \\
\hline$F P$ & Final product & & \\
\hline Parameters & & Unit RM & Unit FP \\
\hline$T$ & Periodic review interval & \multicolumn{2}{|l|}{ days } \\
\hline OUTL & Order Up To Level & \multicolumn{2}{|l|}{ units } \\
\hline SS & Safety Stock & $\mathrm{kg}$ & units \\
\hline$L T$ & Procurement lead time & \multicolumn{2}{|l|}{ days } \\
\hline$O$ & Order quantity & $\mathrm{kg}$ & units \\
\hline$I$ & Inventory position & \multicolumn{2}{|l|}{ units } \\
\hline $\bar{I}$ & Average quantity of material in stock & $\mathrm{kg} / \mathrm{day}$ & units/day \\
\hline $\bar{T}$ & Average time of material in stock & \multicolumn{2}{|l|}{ days } \\
\hline$D$ & Demand of the downstream player/s & \multicolumn{2}{|l|}{ units } \\
\hline$\mu_{d}, \sigma_{d}$ & Customer demand; mean and standard deviation & \multicolumn{2}{|l|}{ units/day } \\
\hline$k$ & Service level & \multicolumn{2}{|l|}{$\%$} \\
\hline$w_{\mathrm{R} M}$ & Weight of raw material & \multicolumn{2}{|l|}{$\mathrm{kg} /$ unit } \\
\hline$Q_{\text {transp }}$ & Total quantity of material transported & \multicolumn{2}{|l|}{$\mathrm{kg} /$ trip } \\
\hline$c_{0}$ & Unitary order cost & \multicolumn{2}{|l|}{$€ /$ order } \\
\hline$c_{b}$ & Unitary cost of holding stock & $€ / \mathrm{kg}$ & $€ /$ unit \\
\hline$c_{\text {transp }}$ & Transportation cost & \multicolumn{2}{|l|}{$€ / \mathrm{kg}$} \\
\hline$P$ & Machine Productivity & \multicolumn{2}{|l|}{ units/day } \\
\hline$Q$ & Production quantity & \multicolumn{2}{|l|}{ units } \\
\hline$N$ & Simulation duration & \multicolumn{2}{|l|}{ days/year } \\
\hline$C_{A M}$ & Amortization cost & \multicolumn{2}{|l|}{$€ /$ unit } \\
\hline$C_{E}$ & Energy cost & \multicolumn{2}{|l|}{$€ /$ unit } \\
\hline$C_{R M}$ & Raw material cost & \multicolumn{2}{|l|}{$€ / \mathrm{kg}$} \\
\hline$C_{L}$ & Labour cost & \multicolumn{2}{|l|}{$€ /$ unit } \\
\hline
\end{tabular}

Table 1. indices and parameters of the simulation model

The quantity ordered by each OEM is calculated considering a forecast based on the demand of the previous month (4 weeks/month):

$$
O_{W}^{O E M}=\frac{D_{m-1} \times w_{R M}}{4} \quad[\mathrm{~kg} / \text { week }]
$$

Moreover, an additional quantity is stocked at the OEM plant to reduce the out of stock risk. The amount of safety stock for raw materials is computed as follows:

$$
S S_{R M}=S S_{F P} \times w_{R M}
$$




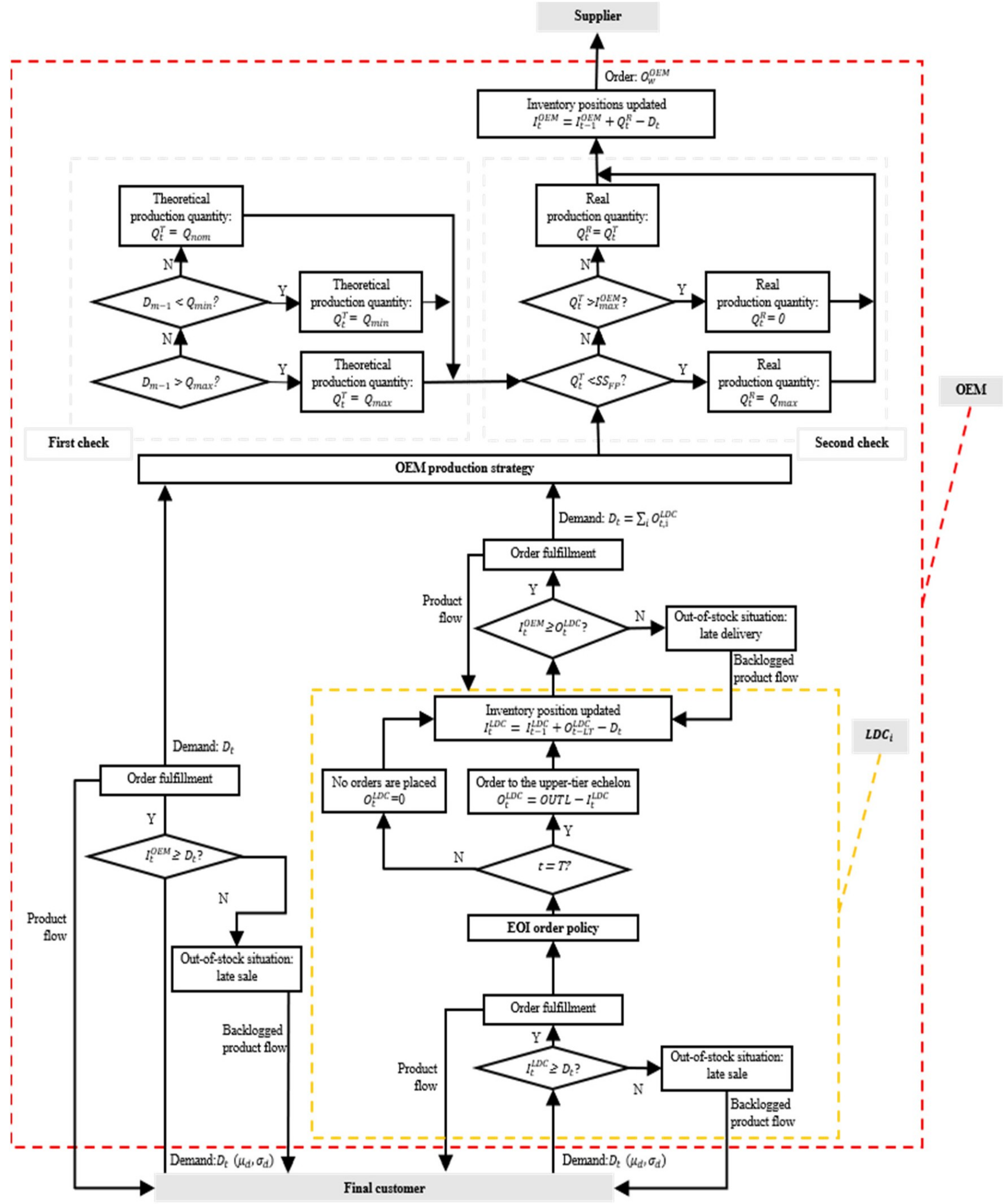

Figure 3. Flowchart of the reorder and production processes

Hence, if the stock of raw material falls below $S S_{R M}$, an additional quantity is added to $O_{w}{ }^{O E M}$ with the aim of restoring the safety stock quantity. The production phase and inventory strategy at the supplier's plant are not included in the model, considering that the player is always able to provide the requested quantity to the manufacturer. Figure 4 shows the flows of both materials and information which manages the Original Equipment 
Manufacturer. In particular, two main areas can be identified: the production management and the inventory management of both raw material and final products.

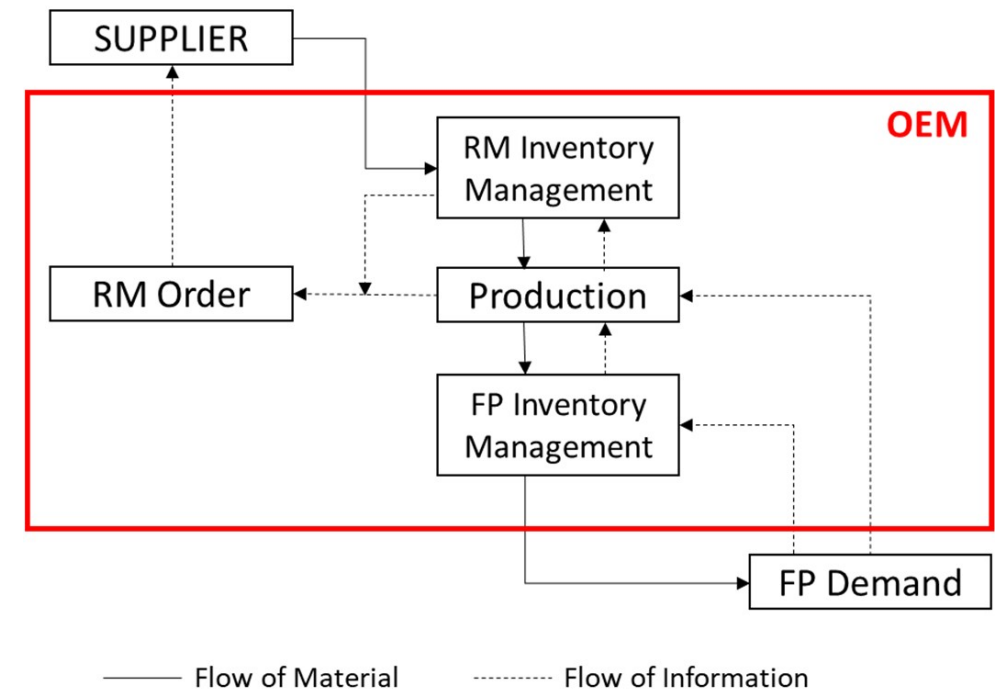

Figure 4. Flows of materials and information at OEM

Looking at the production stage, the model has been programmed with the aim of introducing a level of flexibility. A nominal production quantity $\left(Q_{n o m}\right)$ is fixed considering the machine productivity and the number of machines. However, the model allows modifying the daily production amount by increasing or decreasing the nominal quantity. In particular, other two possible levels of production are defined: the minimum and the maximum production quantity $\left(Q_{\min }\right.$ and $Q_{\text {max }}$ respectively), which are computed considering a decrease or increase respect to the nominal amount. A double check has been introduced with the aim of simulating the behavior of the OEM considering the flexibility of the additive technology. In particular:

- First check: each month, the theoretical production quantity $\left(Q_{t}^{T}\right)$ is identified by considering the previous month demand and the production capacity of the plant. The OEM selects the production level choosing between $Q_{\text {nom }}, Q_{\text {min }}$ and $Q_{\text {max }}$.

- Second check: each day, the real production quantity is defined considering the current stock level $\left(Q_{t}^{R}\right)$. In particular, if the inventory position is found to be lower than the safety stock, $Q_{\max }$ is produced. On the contrary, no production is scheduled if the inventory level exceeds a fixed maximum level $\left(I_{\text {max }}^{O E M}\right)$, which represents the storage physical capacity. Otherwise, the theoretical production quantity is confirmed.

Finally, the inventory level of final products at OEM is updated each day, as follows:

$$
I_{t}^{O E M}=I_{t-1}^{O E M}+Q_{t}^{R}-D_{t}
$$

At this stage, a distinction between the two configurations is needed. In fact, the OEMs belonging to the decentralized Supply Chain directly face the final user. In such case, each OEM directly sees the customer demand. Instead, the Centralized structure includes a distribution level composed of some local distribution centers. Therefore, each OEM receives a daily demand that is computed as the sum of the orders of the downstream players. Figure 5 shows the main flows implemented in the simulation model to reproduce the inventory process managed by the distribution centers. 


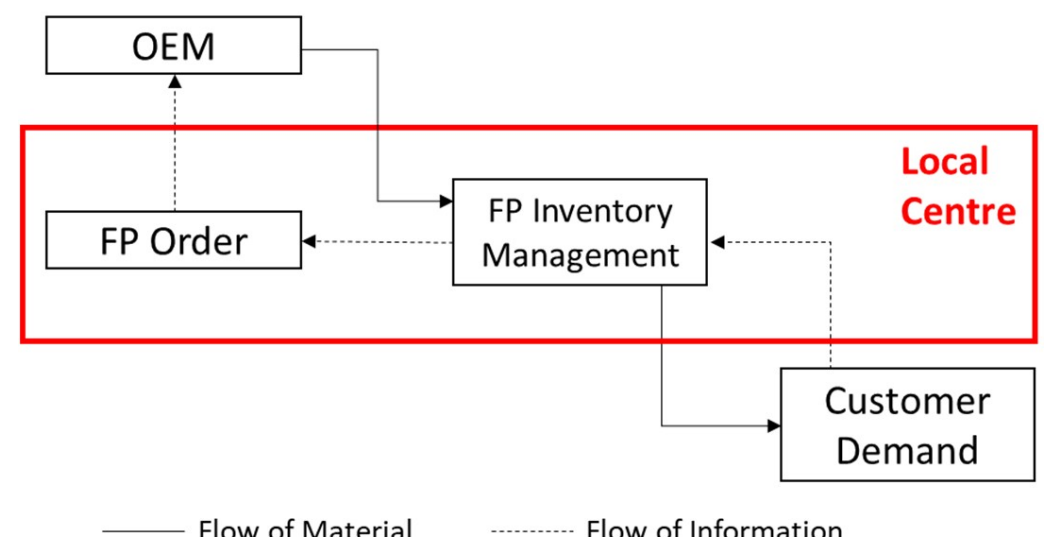

Figure 5. Flows of materials and information at Local distribution center

An Economic Order Interval (EOI) policy has been modelled as inventory strategy. Such reorder policy is based on periodic reviews and variable order quantities. In fact, at fixed periodic interval $(T)$, the inventory level is checked and an order is placed considering the current inventory position. The quantity ordered allows raising the current stock to the order-up-to level (OUTL) which is the level of stock that should allow to satisfy the customer demand since the next order. The following equations have been inserted in the model:

$$
\begin{gathered}
T=\sqrt{\frac{2 C o}{C_{h^{*}} \mu_{d}}} \\
O U T L=\overline{\mu_{d}} *(T+L T)+S S_{F P}
\end{gathered}
$$

Where,

$$
S S=k \sigma_{d} \sqrt{L T+T}
$$

The order placed at time $\mathrm{T}$ by each local distribution center is calculated as:

$$
O_{t}^{L D C}=O U T L-I_{t}^{L D C}
$$

Where, the inventory position at each time $t$ is computed considering the stock quantity at $t-1$, the order placed at $t$ $L T$ and received at $t$ and the demand of the final customer satisfied at $t$.

$$
I_{t}^{L D C}=I_{t-1}^{L D C}+O_{t-L T}^{L D C}-D_{t}
$$

Finally, the model considers the back orders, thus if the OEM is not able to provide the right quantity to the distribution center, he sends all the available amount and the remaining quantity is shipped with a late delivery. In the same way, if possible, the LDC sells the product to the final customer in time; however, stock out situations could occur, and in such case late sales are planned.

\subsection{Key Performance Indicators}

Some key performance indicators (KPI) have been identified in order to assess and compare the performance of the two configurations. The KPIs have been chosen considering suitable indexes proposed in literature for a quantitative assessment of supply chain performance (Piotrowicz \& Cuthbertson, 2015), but also benefits and challenges due to the additive manufacturing technology (Delic, Eyers \& Mikulic, 2019). Economic and strategic metrics have been considered to measure the supply chain performance. Moreover, both the OEM and the whole supply chain efficiency have been evaluated. The following KPIs are proposed: 
(1) Number of machines (M). It reflects the total amount of machines considering all the OEMs of the system $(i=1, \ldots m)$. It depends on the machine productivity and the expected production quantity:

$$
M=\sum_{i=1}^{m} \frac{\mu_{d}}{P} \quad \text { [number }
$$

(2) Unit product cost $\left(C_{F P}\right)$. It reflects the unit cost of the final product. It is calculated adding up several contributions, according to the following formula:

$$
C_{F P}=C_{A M}+C_{E}+\left(C_{R M} * w_{R M}\right)+C_{L} \quad[€ / \text { unit }]
$$

(3) Supply Chain Lead Time (SCLT). It represents the time needed by the supply chain to transform raw material into final product and to deliver it to the final customer. It considers the total procurement lead time between the $n$ echelons and the average time in stock of both raw material and final product. All the parameters depend on the SC characteristics and the number of actors:

$$
S C L T=\bar{T}_{R M}+\sum_{j=1}^{n} L T_{j}+\bar{T}_{F P} \quad[\text { days }]
$$

(4) Average holding stock $\left(\bar{I}_{F P}\right)$. It evaluates the average physical inventory, considering all the players $(p=1, \ldots m)$ who stock the final product:

$$
\bar{I}_{F P}=\sum_{p=1}^{m} \bar{I}_{F P p} \quad[\text { unit/day }]
$$

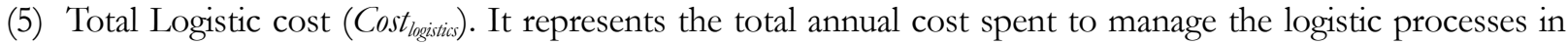
terms of inventory management and transport management:

$$
\operatorname{Cost}_{\text {Logistics }}=\operatorname{Cost}_{H S}+\operatorname{Cost}_{T} € / \text { year }
$$

In particular, the total Holding Cost $\left(\operatorname{Cos}_{H S}\right)$ reflects the cost of storing both raw material and final product; two contributions are computed starting from the average physical inventory and the unit cost of holding stock. A total amount is computed considering all the players of the network:

$$
\operatorname{Cost}_{H S}=\left(\bar{I}_{R M} \cdot c_{h, R M} \cdot N\right)+\left(\bar{I}_{F P} \cdot c_{h, F P} \cdot N\right) \quad € / \text { year }
$$

The total Transport Cost $\left(\operatorname{Cost}_{T}\right)$ indicates the cost of moving both raw material and final product and it is computed by considering all the deliveries of the year. In both cases, it is calculated starting from the amount of material transported and the unitary cost to transport it. Moreover, the unit transport cost depends on the distance travelled:

$$
\text { Cost }_{\text {trip }}=Q_{\text {transp }} \cdot c_{\text {transp }} € / \text { trip }
$$

Obviously, all the z trip of the year are considered.

$$
\operatorname{Cost}_{T}=\sum_{k=1}^{Z} \operatorname{Cost}_{\text {trip }_{k}} \quad € / \text { year }
$$

\section{Numerical Application}

A numerical example is proposed to analyze the response of the system according to the supply chain structure. Different input data have been tested in order to assess the supply chain performance varying a set of factors. The aim is to identify and study the key drivers which could influence the design of the SC structure. Five different factors have been investigated considering different levels (Table 2). Factors have been chosen starting from the 
analysis of the current literature, which suggests the evaluation of some important aspects that influence the design of a supply chain adopting the additive technology. A brief description is provided below:

- Customer demand in terms of mean and standard deviation. The average number of units needed by the final user has to be suitable to justify the investment on production capacity; otherwise a demand aggregation is needed ( $\mathrm{Li}$ et al., 2019). Instead, the variability of the demand generates uncertainties, which results in inefficiencies including over-production, safety stocks, and service loss (Sasson \& Johnson, 2016).

- Service level. It represents the quality of the service provided by the supply chain which can affect all the logistic parameters, such as supply chain lead time, total holding stocks and number of transport. (Rinaldi, Caterino, Fera et al., 2021).

- Geographic distribution. The distance between players and echelons can influence supply chain decisions at strategic, tactical and operational levels. (Ryan et al., 2017).

- Machine type. Investment in AM production capacity and knowledge is still expensive, and the influence on manufacturing location due to cost and performance of the machine should be investigated (Kunovjanek et al., 2020)

In addition, the average value is set in the simulation model in terms of units a day requested by the final customers, while the standard deviation has been defined as percentage of the average value. The service level is typically expressed as a percentage, and it represents the expected probability of not hitting stock-out situations. Looking at geographic distribution, it is common to distinguish between regional and national distribution (Rushton, Croucher \& Baker, 2014), while machine type refers to the cost of the equipment.

Starting from the considerations above, different levels have been identified with the aim of evaluating the response of the supply chain. Overall 5 (mean values) x 5 (std. dev. values) x 5 (service level) x 2 (geographic distribution) x 2 (machine type) $=500$ different experiments have been planned. Moreover, since the final customer demand is described as a normal distribution, 25 replications per experiment have been run. For each experiment, the simulation model provides the results for the two supply chain configurations.

\begin{tabular}{|c|c|c|c|c|c|}
\hline Factor & \multicolumn{5}{|c|}{ Level } \\
\hline & 1 & 2 & 3 & 4 & 5 \\
\hline Demand (mean) & 16 & 76 & 136 & 196 & 256 \\
\hline Demand (Std.dev.) & $5 \%$ & $10 \%$ & $15 \%$ & $20 \%$ & $25 \%$ \\
\hline Service Level & $75 \%$ & $80 \%$ & $85 \%$ & $90 \%$ & $95 \%$ \\
\hline Geographic distribution & Regional & National & & & \\
\hline Machine type & Low-cost & High-cost & & & \\
\hline
\end{tabular}

Table 2. Plan of experiment

Obviously, the last two factors implicate changes in several input data. In particular, the geographic distribution affects two different input parameters: the distance between the players, and the related procurement lead time. A real Italian supply chain has been considered to define the distance between players. The following distances have been considered Table 3 .

Procurement lead time has been set according to the distance provided in Table 3. In particular, if the distance between players is lower than $100 \mathrm{~km}$, the lead time is considered equal to 1 day. If the distance ranging from 100 to 500 , the lead time is set at 2 days. Otherwise, 3 days are needed to prepare and deliver the order.

Table 4 presents the input data depending on the machine type.

Table 5 reports the rest of the input data used to compute the KPIs and compare the two supply chain configurations (Rinaldi, Caterino, Manco, Fera \& Macchiaroli, 2021). 
Finally, transportation cost $\left(c_{t}\right)$ depends on the distance travelled. For distance lower than $700 \mathrm{~km}$, the unitary cost has been set to $0.16 € / \mathrm{kg}$, otherwise it is set to $0.35 € / \mathrm{kg}$.

\begin{tabular}{|c|r|r|r|r|r|r|r|r|r|r|r|}
\hline Distribution type & \multicolumn{10}{|c|}{ Distance [km] } \\
\hline Regional & OEM1 & OEM2 & LDC1 & LDC 2 & LDC 3 & LDC 4 & LDC 5 & LDC 6 & LDC 7 & LDC 8 \\
\hline Supplier & 36 & 70 & 18 & 34 & 43 & 28 & 58 & 118 & 15 & 114 \\
\hline OEM1 & & & 28 & 33 & 19 & 13 & & & & \\
\hline OEM2 & & & & & & & 44 & 54 & 51 & 74 \\
\hline National & OEM1 & OEM2 & LDC1 & LDC 2 & LDC 3 & LDC 4 & LDC 5 & LDC 6 & LDC 7 & LDC 8 \\
\hline Supplier & 931 & 840 & 661 & 665 & 881 & 811 & 870 & 730 & 475 & 472 \\
\hline OEM1 & & & 377 & 285 & 415 & 144 & & & & \\
\hline OEM2 & & & & & & & 344 & 202 & 501 & 393 \\
\hline
\end{tabular}

Table 3. Geographic distribution - experimental setup

\begin{tabular}{|l|r|r|r|}
\hline \multicolumn{1}{|c|}{ Machine type } & Machine cost [€] & \multicolumn{1}{c|}{ Cycle time [h/unit] } & Productivity [unit/day] \\
\hline Low-cost & $165^{\prime} 000.00$ & 12.51 & 1.92 \\
\hline High-cost & $390^{\prime} 000.00$ & 5.35 & 4.48 \\
\hline
\end{tabular}

Table 4. Machine type - experimental setup

\begin{tabular}{|l|r|c|}
\hline \multicolumn{1}{|c|}{ Parameter } & Input data & Measurement unit \\
\hline Weight of raw material & 1.88 & $\mathrm{~kg} / \mathrm{unit}$ \\
\hline Weight of final product & 1.73 & $\mathrm{~kg} / \mathrm{unit}$ \\
\hline Order cost & 100 & $€ /$ order \\
\hline Cost of holding stock - Raw material & 0.66 & $€ / \mathrm{kg}$ \\
\hline Cost of holding stock - Final product & 1.5 & $€ /$ unit \\
\hline
\end{tabular}

Table 5. Input data

\section{Results and Discussion}

In this section, the results of the simulations are analyzed and discussed. In particular, the AM centralized and AM decentralized scenarios have been compared relying on some KPIs which give general information about the performances of the supply chain. From the full plan of experiments described above, it has arisen that some factors have a greater influence on the specific KPIs than others. Thus, the results are presented considering only the dependence of the KPI on the most important factors. In particular, the factor that mostly affects the trend of the KPI can be considered as a "primary factor" and will be represented on the $\mathrm{x}$-axis, while the other influencing factors will be shown only considering the lower and higher level ("low-high"). Finally, factors, which do not affect the KPI, will be fixed ("fix"). Table 6 introduces all the KPIs and factors analyzed and the set of experiments tested.

It is worth to note that all the investigated KPIs can be interpreted as economic drivers; thus, the focus of the analysis is on the economic perspective, looking at the differences among the centralized and decentralized supply chains adopting additive manufacturing technologies. The first analysis focuses on the Unit product cost $\left(C_{F P}\right)$, varying the average daily demand and the type of the machine; the trend of $C_{F P}$ is shown in Figure 6. 


\begin{tabular}{|c|c|c|c|c|c|}
\hline \multirow[b]{2}{*}{ KPI } & \multicolumn{5}{|c|}{ Factors } \\
\hline & $\begin{array}{l}\text { Demand } \\
\text { (mean) }\end{array}$ & $\begin{array}{l}\text { Demand } \\
\text { (Std.dev.) }\end{array}$ & $\begin{array}{l}\text { Service level } \\
\text { (SL) }\end{array}$ & $\begin{array}{c}\text { Geographic } \\
\text { distribution (GD) }\end{array}$ & $\begin{array}{l}\text { Machine } \\
\text { type (MT) }\end{array}$ \\
\hline Unit product cost & Primary factor & Fix & Fix & Fix & Low-high \\
\hline Number of machines & Primary factor & Fix & Fix & Fix & Low-high \\
\hline Supply Chain Lead Time & Fix & Low-high & Primary factor & Low-high & Fix \\
\hline Average Holding Stock & Primary factor & Low-high & Low-high & Fix & Fix \\
\hline Total Logistic cost & Low-high & Primary factor & Low-high & Fix & Fix \\
\hline
\end{tabular}

Table 6. List of evaluated KPIs and related influencing factors
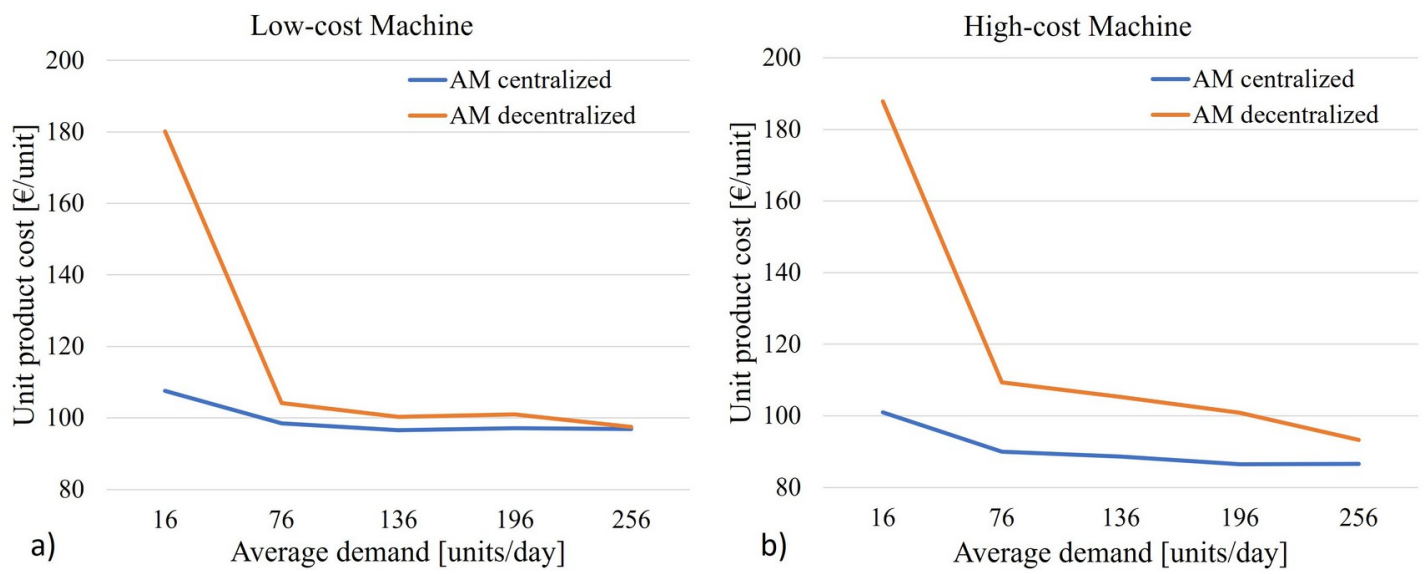

Figure 6. Unit product cost (Fix factors: Std.dev. $=10 \%, \mathrm{SL}=80 \%, \mathrm{GD}=$ national)

By Analyzing Figure 6, it seems clear that increasing the value of the demand, $C_{F P}$ generally decreases. By moving from an average demand of 16 units per day to $256, C_{F P}$ becomes almost a half in both the proposed scenarios of the decentralized supply chain. Such result can be explained by looking at the machine capacity utilization, which is very low for low demand in the decentralized configuration (39,9\% for low-cost machines and 40,1\% for high-cost one). In fact, the unit product cost is strongly affected by the amortization cost of the additive machine, and a low utilization leads to split the cost of machine on few units. Because of the structure of the SC, such phenomena is less significant in the centralized solution, where the capacity utilization is quite low for low demand, but it reaches the $66,2 \%$ for the high-cost machine. In general, the $C_{F P}$ decreases when the average demand increases in both types of supply chains because of the increase of the capacity utilization. Obviously, the capacity utilization and the amortization cost depend on the type of machine. In Figure 6a, the trends of the two supply chain configurations are very similar. In fact, excluding the first level of average demand (16 units a day), the 2 curves are almost overlapping, since the additive machine is not very expensive and, consequently, the impact of the amortization cost combined with the capacity utilization is not so evident. On the contrary, when a high-cost machine is used (Figure 6b), the difference in the capacity utilization strongly influences the amortization costs, which are obviously reflected on $C_{F P}$; hence, the difference between the two supply chains becomes greater.

Moreover, the two types of AM machines differ not only for the cost, but also for the production camera volume and the type of technology used for producing the build, which affects the speed of production. Comparing the two types of machines (Figure 6a vs Figure 6b), it is very interesting to note that $C_{F P}$ is always smaller, in absolute terms, when using a high-cost machine in a centralized configuration. Such result denotes that a machine with a higher production camera volume and speed seems to be better than a cheaper machine, but with worst performance. Considering the decentralized solution, the same consideration can be made for high demand, when the capacity utilization justifies the investment. 
This last consideration allows introducing the next KPI, i.e. the number of machines needed for both the configurations. Such KPI has been evaluated varying the average demand. Figure 7 presents a comparison between the 2 types of machines for the same supply chain configuration (Figure $7 \mathrm{a}$ and $7 \mathrm{~b}$ ), and a related table showing the corresponding total cost of machines (Figure $7 \mathrm{c}$ and $7 \mathrm{~d}$ ).

AM centralized

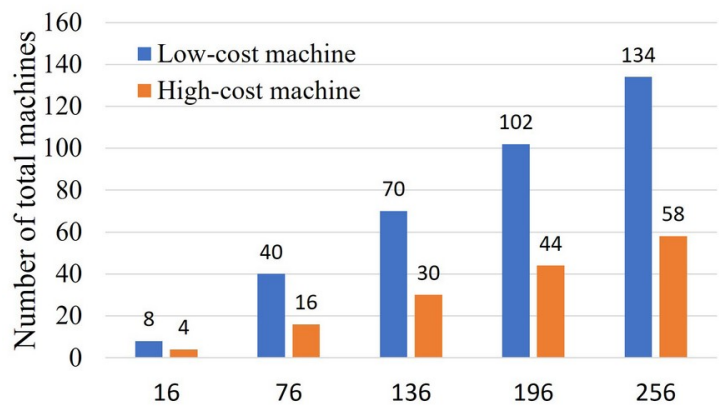

a)

\begin{tabular}{|c|c|c|}
\hline $\begin{array}{c}\text { Average } \\
\text { demand }\end{array}$ & \multicolumn{2}{|c|}{ Total cost of machines } \\
\hline & Low-cost machine & High-cost machine \\
\hline 16 & $1.320 .000,00 €$ & $1.560 .000,00 €$ \\
\hline 76 & $6.600 .000,00 €$ & $6.240 .000,00 €$ \\
\hline 136 & $11.550 .000,00 €$ & $11.700 .000,00 €$ \\
\hline 196 & $16.830 .000,00 €$ & $17.160 .000,00 €$ \\
\hline 256 & $22.110 .000,00 €$ & $22.620 .000,00 €$ \\
\hline C)
\end{tabular}

AM decentrilized

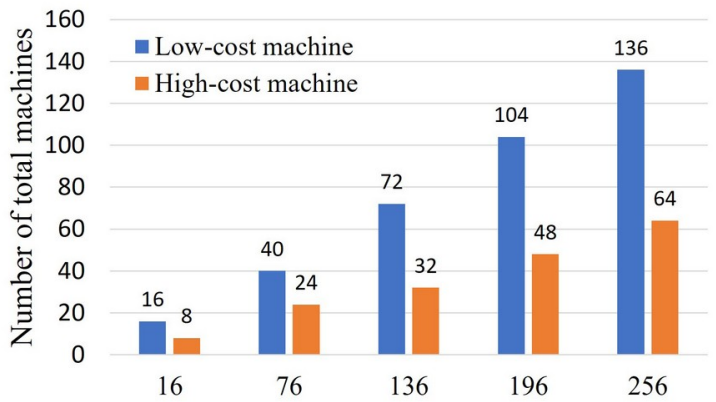

b)

Figure 7. Number of machines and Total machine investment (Fix factors: St.Dev. $=10 \%, \mathrm{SL}=80 \%, \mathrm{GD}=$ national)

Obviously, the number of machines increases according to the average demand, even though the rate of growth is different for the two types of machine because of their different characteristics and technology. In fact, the High-cost machine is faster in producing the builds than the Low-cost machine and this aspect leads to need a significant smaller number of machines in both the supply chain configurations (Figure 7a and Figure 7b). Moreover, it is very interesting to note that the High-cost machine seems to be particularly suitable for the centralized configuration. In fact, the total cost of the fleet of machines for each average demand is very similar to the cost of the Low- cost fleet; the difference ranges from $-5,8 \%$ (which means the fleet cost of the High-cost machine is lower than the Low-cost one) to the 18\%, with the advantage to have a smaller number of machines (Figure 7c). In the decentralized configuration, the number of Low-cost machines is very similar to the centralized solution, while the number of High-cost machines increases (Figure 7a vs Figure 7b). This aspect is related to a combination of factors, i.e. the characteristics of the decentralized structure and the production capacity of the machine. In fact, the decentralized structure needs a higher minimum number of machines to satisfy the customer and guarantee a good service level, and the high machine productivity amplifies the difference. Looking at Figure $7 \mathrm{~d}$, it can be noticed that the cost of the High-cost fleet is significantly higher than Low-cost fleet, reaching a maximum difference of the 41,8\%; hence, the use of Low-cost machines seems to be the best solution in the decentralized supply chain.

The third KPI is strongly related to the performance of the whole supply chain. In particular, the SCLT has been represented as a function of the service level (Figure 8). Moreover, the geographical distribution and high and low levels of demand standard deviation have been tested. The first important consideration is that the SCLT is always smaller in the decentralized configuration than the centralized one. Such parameter depends on both the average time in stock (raw material and final product) and the time needed to transport the material between two players (procurement lead time). Since the OEMs directly face the final customer, the decentralized configuration has one echelon less than the centralized one; thus, a shorter supply chain leads to a reduction of the transportation time 
with resulting benefits in the SCLT. Moreover, the average quantity in stock of final product should increase in the centralized SC because of the bullwhip effect, with a consecutive increase in the average time in stock. Concerning raw material, the expected behavior is opposite; in fact, each OEM of the decentralized SC needs a minimum stock of raw material, which brings to have a higher total amount of powder in stock. Overall, the simulation results confirm a better SCLT in all cases for the decentralized supply chain configuration (Figure 8).

Concerning the variation of the SCLT associated to the service level, since the centralized configuration is less flexible, it is the most affected by the SL increase, especially when the Std.dev. is high (Figure 8c and Figure 8d). In such case, the SCLT reaches an increment of more than $5 \%$, while the SCLT seems to not vary increasing the SL in the decentralized solution, with a maximum increment of the $0,57 \%$. In general, the decentralized structure is able to better respond to suddenly changes, thus it is less affected by the variability of the demand, which causes a stronger increase of the average stock and the related average time in stock in the centralized structure.

In order to better understand the impact of the standard deviation on the SCLT, Figure $8 \mathrm{a}$ vs Figure 8c, and Figure $8 \mathrm{~b}$ vs Figure $8 \mathrm{~d}$ are compared. In both cases, the SCLT increases by increasing the standard deviation because of the greater uncertainty. In fact, the safety stock of both raw materials and final products increases when the St.dev. grows, leading to an increment of the average time in stock and a resulting increment of the SCLT. As already mentioned, the centralized configuration is more affected by such factor. For instance, considering SL=95\% and $\mathrm{GD}=$ national, the centralized configuration shows a percentage increase of $4.7 \%$ when moving from St.dev. $=5 \%$ to St.dev. $=25 \%$ (Figure $8 \mathrm{~b}$ vs Figure $8 \mathrm{~d}$ ). This aspect is not so evident in the decentralized supply chain, since there is a better inventory management, which brings to an increment of $0,9 \%$ considering $\mathrm{SL}=95 \%$ and $\mathrm{GD}=$ national (Figure $8 \mathrm{a}$ vs Figure 8c).

Furthermore, another interesting result can be seen by comparing the SCLT trend varying the geographical distribution (Figure 8a vs Figure 8b; Figure 8c vs Figure 8d). In particular, moving from a regional to a national distribution, the SCLT increases for both the supply chain configurations, but with different rate of growth. In fact, the increment of the SCLT for the AM centralized configuration ranges from 31,2\% to 32,1\% for each SL considered while for the decentralized structure it is always around $21,1 \%$. Hence, by increasing the distance between players, the decentralized structure improves the performance compared to the centralized one.

Figure 9 shows the trend of the average holding stock of the final product varying the average demand. The effect of the demand standard deviation and the service level have been investigated.
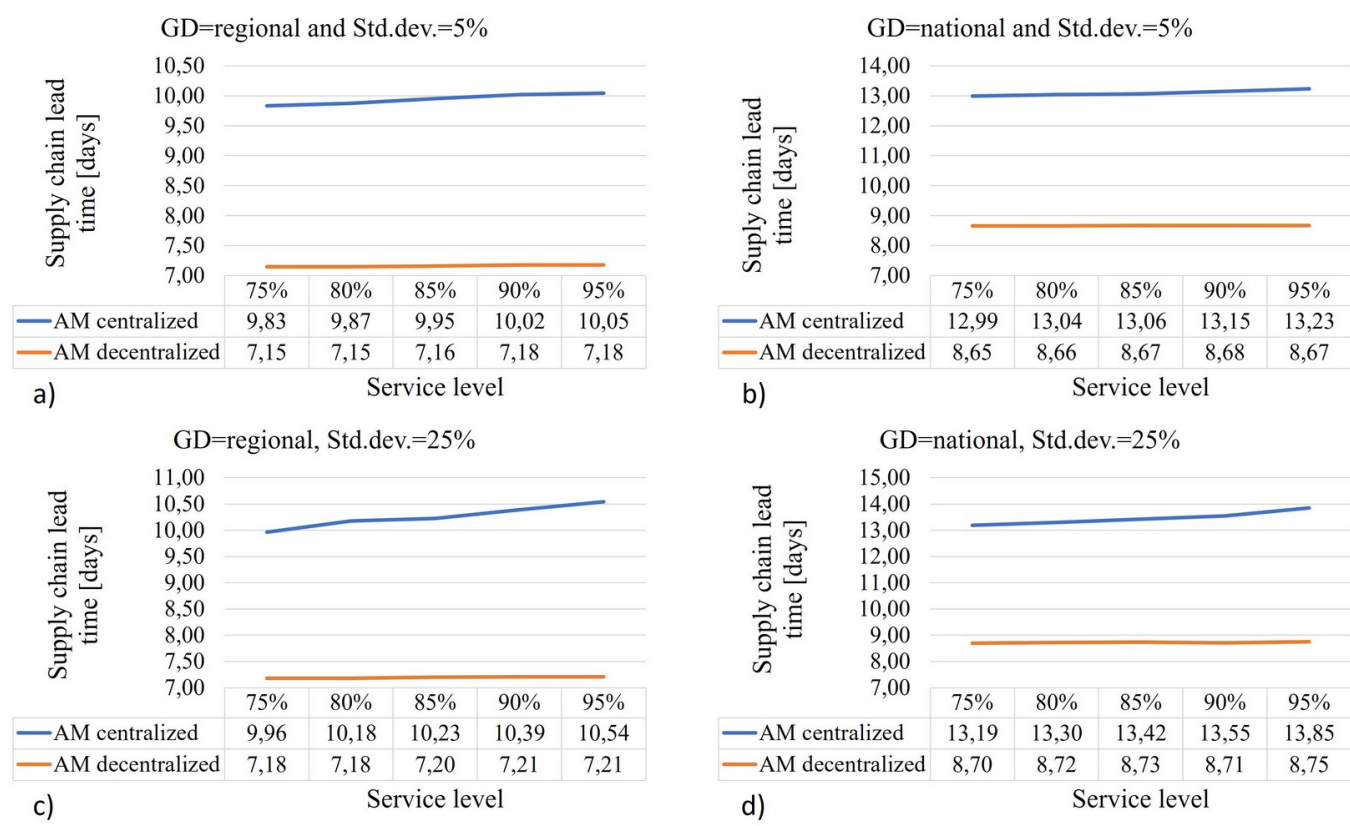

Figure 8. Supply chain lead time (Fix factors: Average Demand=136 units/day, MT=High-cost) 

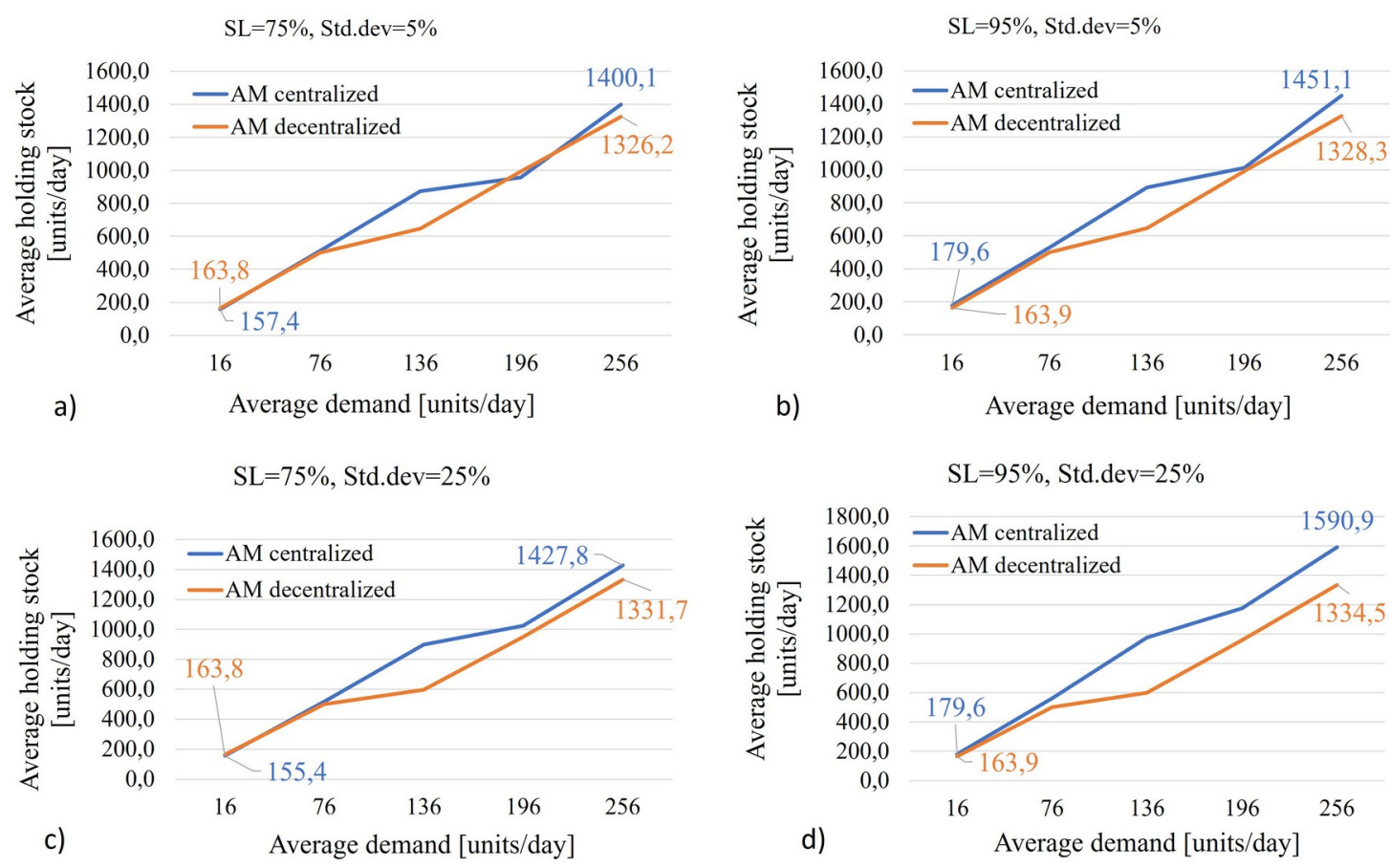

Figure 9. Average holding stock of final product (Fix factors: GD=national, MT=High-cost)

Obviously, $\bar{I}_{F P}$ increases when the average daily demand increases, but it is interesting to study its behavior combining different levels of SL and Std.dev. First, the SL variation is analyzed comparing Figure 9a vs Figure 9b, and Figure 9c vs Figure 9d. It is possible to notice that the decentralized solution is not affected by the SL, since the values remain constant moving from $\mathrm{SL}=75 \%$ to $\mathrm{SL}=95 \%$. Instead, the SL strongly affects the centralized configuration, increasing the average stock. Such effect is more evident when the standard deviation is high (Figure $9 \mathrm{c}$ vs Figure 9d). The same behavior can be observed by studying the variation of the Std.dev. (Figure 9a vs Figure 9c, and Figure 9b vs Figure 9d). In fact, the standard deviation mainly affects the centralized configuration, increasing the final product in stock, while a slightly rise is seen in the decentralized configuration. Moreover, considering the centralized configuration, the combination of the two factors (Std.dev. and SL) amplifies the negative effect on the average holding stock of the final product (Figure 9a vs Figure 9d), with an increase of $13.5 \%$ for high level of average demand (256 units a day).

The reason of such behavior is due to the particular configurations of the supply chains. In fact, the centralized configuration has a higher number of echelons, which leads to increase the bullwhip effect. In fact, when SL and St.dev. increase, each player of each level of the centralized SC tends to increase the safety stock to respond to the market requests. On the contrary, the OEMs of the decentralized solution directly face the customer, allowing to better manage the market changes.

The last analysis is related to the Total Logistic cost, composed of two main contributions: the total Holding Cost and the total Transport Cost, which consider the inventory management and transportation of both raw materials and final products. In particular, the Cost togistics has been analyzed varying the standard deviation of the demand, and considering low and high levels of service level and average demand (Figure 10). It is important to notice that the trends are in line with the previous results and considerations. In fact, in the decentralized configuration the Costhogitis slightly increases by increasing the Std. dev, which has a stronger effect on the centralized configuration. The impact becomes more evident with a high service level (Figure 10b and Figure 10d), especially for a high level of demand, reaching a difference of 7,4\% moving from Std.dev $=5 \%$ to Std.dev $=25 \%$ (Figure 10d). As expected, moving from low to high SL, the logistic cost increases because the need of a greater safety stock (Figure 10a vs Figure 10b; Figure 10c vs Figure 10d). Moreover, the influence of the average demand is also evident by comparing Figure 10a vs Figure 10c and Figure 10b vs Figure 10d, where the increment of the cost is due to the growth of the holding cost and transport cost related to the greater quantities managed by the SC. 

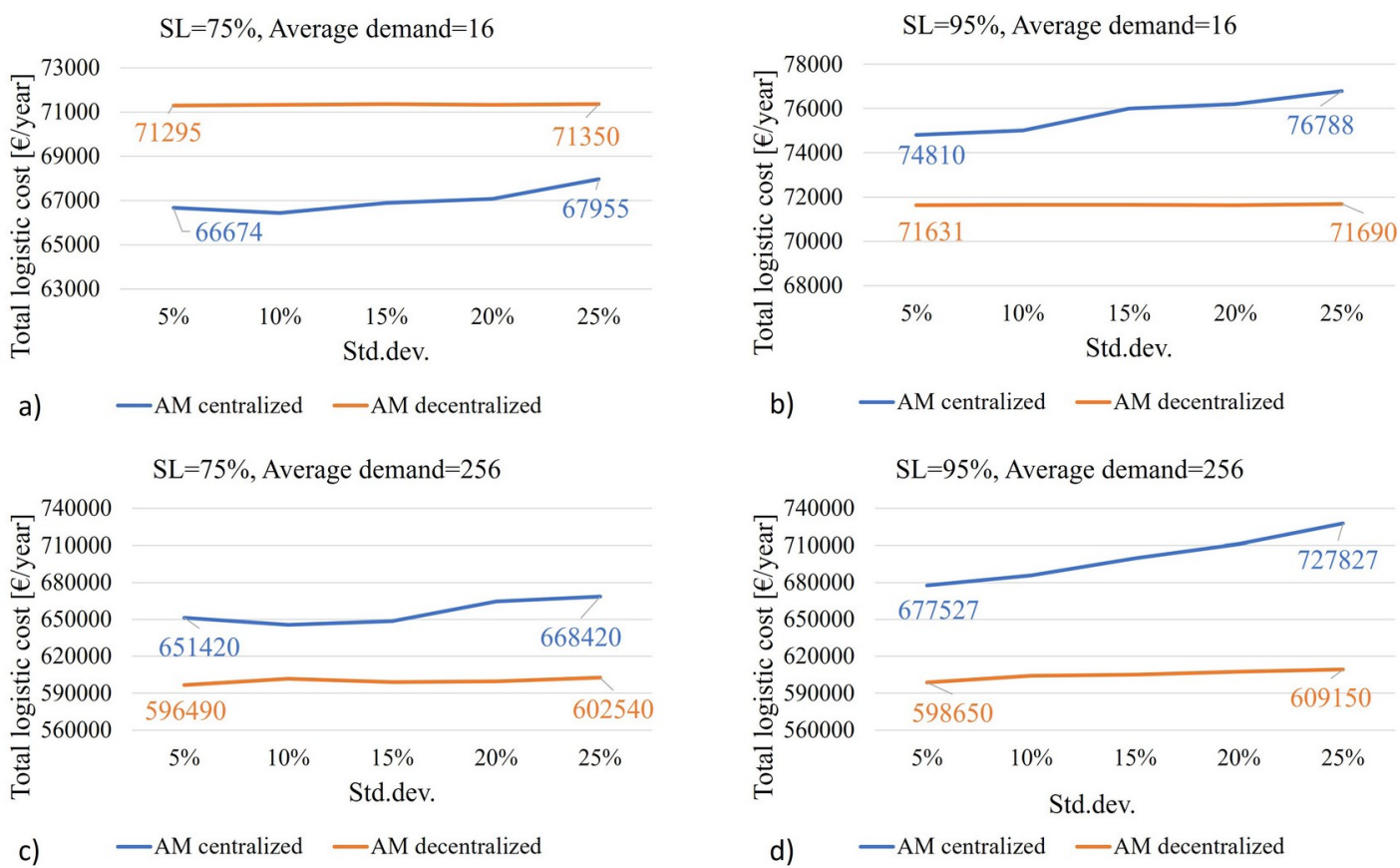

Figure 10. Total Logistic cost (Fix factors: $G D=$ national, $M T=H i g h-\cos t)$
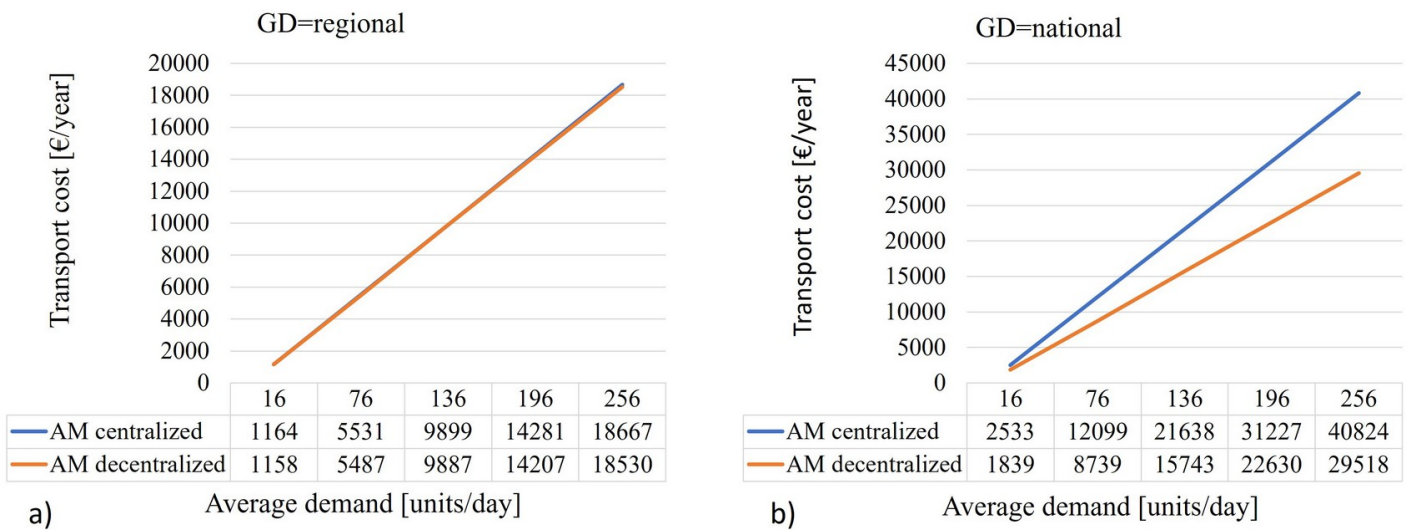

Figure 11. total Transport Cost (Fix factors: Std.Dev. $=10 \%, \mathrm{SL}=80 \%, \mathrm{MT}=$ High-cost)

It is very interesting the result reached setting a low service level and a low average demand (Figure 10a). In particular, the Cost togitisis is smaller in the centralized SC than in the decentralized SC. The result is due to the particular combination of the two factors. In general, for low level of SL, the average stock is low and the related bullwhip effect is limited; in this particular situation, the two configurations have a very similar amount of final product in stock. Such effect is stronger for low levels of demand. However, the average stock of raw material is higher in the decentralized solution because of the higher number of OEMs. Moreover, the study considers an Italian context, where the distances among different regions are not very high if compared with bigger countries; for such reason, the influence of the transportation cost is very limited. The combination of all that factors leads to support the adoption of a centralized structure when SL and average demand are low and distances among players are limited.

As mentioned, the total logistic cost depends on the total Transport Cost $\left(\operatorname{Cos}_{T}\right)$, which has a limited impact respect to the total Holding Cost. In particular, it accounts for $6,8 \%$ for the centralized SC and the 5,3\% for the decentralized SC. Its trend is presented since it provides interesting information. In particular, its behavior has been analyzed varying the average demand and considering different geographical distributions (Figure 11).

The first consideration is linked to the type of geographical distribution. Looking at Figure 11a, which represents a regional distribution (hence, small distances to cover), the transport cost is very similar for the two supply chains, 
with a small difference advantaging the decentralized configuration. For greater distances (Figure 11b), the difference between the two SC becomes more clear, and the difference increases increasing the average demand. Such outcomes depend on the configuration and the specific geographical context. In general, a shorter supply chain allows reducing the transport cost. However, when the distance among players is very short, the benefits in adopting a decentralized SC are very limited.

\section{Conclusions}

In recent years, the impact of additive manufacturing on supply chain performance have been investigated. However, the current literature presents few quantitative studies focusing on the impact of additive manufacturing on the supply chain configuration. The aim of this study is to evaluate the performance of different supply chain configurations adopting additive manufacturing. In particular, the response of different supply chain configurations to different input factors has been investigated. A discrete event simulation model has been developed in order to reproduce the behavior of the players according to their role and position in the network. Many scenarios have been tested with the aim of identifying the best application of the AM considering different combinations of factors. To this purpose, five different input factors have been varied and six key performance indicators have been calculated considering on both manufacturing and logistic processes.

Some interesting results have been obtained from the simulations. In general, the outcomes confirm a better logistic performance for the decentralized configuration respect to the centralized one. Moreover, the decentralized configuration seems to be more flexible, suitable for high service levels, and less affected by the variability of the demand. However, the logistic performance of the two configurations becomes very similar for low levels of demand and when the quality of the service provided by the supply chain is low. Moreover, when the distances among players are very short, the benefits in adopting a decentralized SC are very limited.

Concerning the performance of the production phase, the machine productivity and the cost of the machine strongly influence the economic benefits reached adopting AM. Hence, the centralized structure allows providing a better capacity utilization decreasing the unit product cost. As expected, such effect decreases when the average demand increases. Moreover, a High-cost machine with higher production camera volume and speed seems to be particularly suitable for the centralized configuration, which is able to exploit its potential. Considering the decentralized configuration, the same consideration can be made for high demand, when the capacity utilization justifies the investment.

The paper has a strong practical implication; in fact, the outcomes obtained from the simulation allow deriving some useful guidelines, which could help practitioners to identify a suitable application of the additive technology. In particular, when the demand is very low, the decentralized structure is not justified regardless of the type of machine and the type of geographical distribution. Instead, when the variability of the demand is high, adopting a decentralized SC is the best solution for maintaining high logistic performances, particularly when the distance among players is high.

Moreover, this study contributes to the literature in several ways. First, the model provides a quantitative evaluation. In addition, we consider the whole supply chain, rather than focusing on a specific player. This is a strong point since it is well known that emerging manufacturing technologies can affect the structure and the performance of a whole supply chain.

Finally, the main limitation of the work is the lack of the environmental dimension. Since AM seems to provide environmental benefits, some indicators could be inserted in the model to test the green potential of the different configurations. Moreover, as future researches, the simulation model could be improved and a heterogeneous production could be investigated.

\section{Acknowledgements}

This work was supported by the University of Campania Luigi Vanvitelli under SCISSOR project - V:alere 2019 program. 


\section{Declaration of Conflicting Interests}

The authors declared no potential conflicts of interest with respect to the research, authorship, and/or publication of this article.

\section{Funding}

The authors received no financial support for the research, authorship, and/or publication of this article.

\section{References}

Achillas, C., Aidonis, D., Iakovou, E., Thymianidis, M., \& Tzetzis, D. (2015). A methodological framework for the inclusion of modern additive manufacturing into the production portfolio of a focu factory. Journal of manufacturing Systems, 37, 328-339. https://doi.org/10.1016/j.jmsy.2014.07.014

Attaran, M. (2017). Additive manufacturing: the most promising technology to alter the supply chain and logistics. Journal of Service Science and Management, 10(03), 189. https://doi.org/10.4236/jssm.2017.103017

Atzeni, E., \& Salmi, A. (2012). Economics of additive manufacturing for end-usable metal parts. The International Journal of Advanced Manufacturing Technology, 62(9-12), 1147-1155. https://doi.org/10.1007/s00170-011-3878-1

Barz, A., Buer, T., \& Haasis, H.D. (2016). A study on the effects of additive manufacturing on the structure of supply networks. IFAC-PapersOnLine, 49(2), 72-77. https://doi.org/10.1016/j.ifacol.2016.03.013

Baumers, M., Dickens, P., Tuck, C., \& Hague, R. (2016). The cost of additive manufacturing: machine productivity, economies of scale and technology-push. Technological Forecasting and Social Change, 102, 193-201.

https://doi.org/10.1016/j.techfore.2015.02.015

Chowdhury, S., Shahvari, O., Marufuzzaman, M., Francis, J., \& Bian, L. (2019). Sustainable design of on-demand supply chain network for additive manufacturing. Iise Transactions, 51(7), 744-765.

https://doi.org/10.1080/24725854.2018.1532134

Delic, M., Eyers, D.R., \& Mikulic, J. (2019). Additive manufacturing: empirical evidence for supply chain integration and performance from the automotive industry. Supply Chain Management, 24 (5), 604-621.

https://doi.org/10.1108/SCM-12-2017-0406

Dwivedi, G., Srivastava, S.K. and Srivastava, R.K. (2017). Analysis of barriers to implement additive manufacturing technology in the Indian automotive sector. International Journal of Physical Distribution \& Logistics Management, 47 (10), 972-991. https://doi.org/10.1108/IJPDLM-07-2017-0222

Franco, D., Ganga, G.M.D., de Santa-Eulalia, L.A., \& Godinho-Filho, M. (2020). Consolidated and inconclusive effects of additive manufacturing adoption: A systematic literature review. Computers \& Industrial Engineering, 148, 106713. https://doi.org/10.1016/j.cie.2020.106713

Ghadge, A., Karantoni, G., Chaudhuri, A., \& Srinivasan, A. (2018). Impact of additive manufacturing on aircraft supply chain performance. Journal of Manufacturing Tecbnology Management, 29 (5), 846-865.

https://doi.org/10.1108/JMTM-07-2017-0143

Huang, R., Riddle, M.E., Graziano, D., Das, S., Nimbalkar, S., Cresko, J. et al. (2017). Environmental and economic implications of distributed additive manufacturing: The case of injection mold tooling. Journal of Industrial Ecology, 21(S1), S130-S143. https://doi.org/10.1111/jiec.12641

Holmström, J., Partanen, J., Tuomi, J., \& Walter, M. (2010). Rapid manufacturing in the spare parts supply chain: alternative approaches to capacity deployment. Journal of Manufacturing Technology Management, 21 (6), 687-697. https://doi.org/10.1108/17410381011063996

Ivanov, D., Dolgui, A., \& Sokolov, B. (2019). The impact of digital technology and Industry 4.0 on the ripple effect and supply chain risk analytics. International Journal of Production Research, 57(3), 829-846.

https://doi.org/10.1080/00207543.2018.1488086 
Jiang, R., Kleer, R., \& Piller, F.T. (2017). Predicting the future of additive manufacturing: A Delphi study on economic and societal implications of 3D printing for 2030. Technological Forecasting and Social Change, 117, 84-97. https://doi.org/10.1016/j.techfore.2017.01.006

Khajavi, S.H., Partanen, J., \& Holmström, J. (2014). Additive manufacturing in the spare parts supply chain. Computers in industry, 65(1), 50-63. https://doi.org/10.1016/j.compind.2013.07.008

Kunovjanek, M., Knofius, N., \& Reiner, G. (2020). Additive manufacturing and supply chains-a systematic review. Production Planning \& Control, 1-21. https://doi.org/10.1080/09537287.2020.1857874

Li, Y., Jia, G., Cheng, Y., \& Hu, Y. (2017). Additive manufacturing technology in spare parts supply chain: a comparative study. International Journal of Production Research, 55(5), 1498-1515. https://doi.org/10.1080/00207543.2016.1231433

Li, Y., Cheng, Y., Hu, Q., Zhou, S., Ma, L., \& Lim, M.K. (2019). The influence of additive manufacturing on the configuration of make-to-order spare parts supply chain under heterogeneous demand. International Journal of Production Research, 57(11), 3622-3641. https://doi.org/10.1080/00207543.2018.1543975

Liu, P., Huang, S.H., Mokasdar, A., Zhou, H., \& Hou, L. (2014). The impact of additive manufacturing in the aircraft spare parts supply chain: supply chain operation reference (scor) model based analysis. Production Planning \& Control, 25(13-14), 1169-1181. https://doi.org/10.1080/09537287.2013.808835

Mohr, S., \& Khan, O. (2015). 3D printing and its disruptive impacts on supply chains of the future. Technology Innovation Management Review, 5(11), 20.

Nyamekye, P., Leino, M., Piili, H., \& Salminen, A. (2015). Overview of sustainability studies of CNC machining and LAM of stainless steel. Physics Procedia, 78, 367-376. https://doi.org/10.1016/j.phpro.2015.11.051

Öberg, C. (2019). Additive manufacturing-digitally changing the global business landscape. European Journal of Management and Business Economics. 28 (2), 174-188. https://doi.org/10.1108/EJMBE-11-2018-0116

Oettmeier, K., \& Hofmann, E. (2016). Impact of additive manufacturing technology adoption on supply chain management processes and components. Journal of Manufacturing Technology Management. 27 (7), 944-968. https://doi.org/10.1108/JMTM-12-2015-0113

Piotrowicz, W., \& Cuthbertson, R. (2015). Performance measurement and metrics in supply chains: an exploratory study. International Journal of Productivity and Performance Management. 64 (8), 1068-1091. https://doi.org/10.1108/IJPPM-04-2014-0064

Pour, M.A., Zanardini, M., Bacchetti, A., \& Zanoni, S. (2016). Additive manufacturing impacts on productions and logistics systems. IFAC-PapersOnLine, 49(12), 1679-1684. https://doi.org/10.1016/j.ifacol.2016.07.822

Rayna, T., \& Striukova, L. (2016). From rapid prototyping to home fabrication: How 3D printing is changing business model innovation. Technological Forecasting and Social Change, 102, 214-224. https://doi.org/10.1016/j.techfore.2015.07.023

Rejeski, D., Zhao, F., \& Huang, Y. (2018). Research needs and recommendations on environmental implications of additive manufacturing. Additive Manufacturing, 19, 21-28. https://doi.org/10.1016/j.addma.2017.10.019

Rinaldi, M., Caterino, M., Fera, M., Manco, P., \& Macchiaroli, R. (2021). Technology selection in green supply chains-the effects of additive and traditional manufacturing. Journal of Cleaner Production, 282, 124554. https://doi.org/10.1016/j.jclepro.2020.124554

Rinaldi, M., Caterino, M., Manco, P., Fera, M., \& Macchiaroli, R. (2021). The impact of Additive Manufacturing on Supply Chain design: a simulation study. Procedia Computer Science, 180, 446-455. https://doi.org/10.1016/j.procs.2021.01.261

Roca, J.B., Vaishnav, P., Laureijs, R.E., Mendonça, J., \& Fuchs, E.R. (2019). Technology cost drivers for a potential transition to decentralized manufacturing. Additive Manufacturing, 28, 136-151.

https://doi.org/10.1016/j.addma.2019.04.010 
Rogers, H., Baricz, N., \& Pawar, K.S. (2016). 3D printing services: classification, supply chain implications and research agenda. International Journal of Physical Distribution \& Logistics Management. 46 (10), 886-907. https://doi.org/ 10.1108/IJPDLM-07-2016-0210

Rushton, A., Croucher, P., \& Baker, P. (2014). The handbook of logistics and distribution management: Understanding the supply chain. Kogan Page Publishers.

Ryan, M.J., Eyers, D.R., Potter, A.T., Purvis, L., \& Gosling, J. (2017). 3D printing the future: scenarios for supply chains reviewed. International Journal of Physical Distribution \& Logistics Management, 47 (10), 992-1014. https://doi.org/10.1108/IJPDLM-12-2016-0359

Sasson, A., \& Johnson, J.C. (2016). The 3D printing order: variability, supercenters and supply chain reconfigurations. International Journal of Physical Distribution \& Logistics Management, 46 (1), 82-94. https://doi.org/10.1108/IJPDLM-10-2015-0257

Storper, M., \& Harrison, B. (1991). Flexibility, hierarchy and regional development: the changing structure of industrial production systems and their forms of governance in the 1990s. Research policy, 20(5), 407-422. https://doi.org/10.1016/0048-7333(91)90066-Y

Tziantopoulos, K., Tsolakis, N., Vlachos, D., \& Tsironis, L. (2019). Supply chain reconfiguration opportunities arising from additive manufacturing technologies in the digital era. Production Planning \& Control, 30(7), 510-521. https://doi.org/10.1080/09537287.2018.1540052

Verboeket, V., \& Krikke, H. (2019). The disruptive impact of additive manufacturing on supply chains: A literature study, conceptual framework and research agenda. Computers in Industry, 111, 91-107. https://doi.org/10.1016/j.compind.2019.07.003

Wang, Y., Blache, R., \& Xu, X. (2017). Selection of additive manufacturing processes. Rapid Prototyping Journal, 23(2), 434-447. https://doi.org/10.1108/RPJ-09-2015-0123

Zhang, Y., Jedeck, S., Yang, L., \& Bai, L. (2019). Modeling and analysis of the on-demand spare parts supply using additive manufacturing. Rapid Prototyping Journal, 25 (3), 473-487. https://doi.org/10.1108/RPJ-01-2018-0027

Journal of Industrial Engineering and Management, 2022 (www.jiem.org)

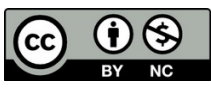

Article's contents are provided on an Attribution-Non Commercial 4.0 Creative commons International License. Readers are allowed to copy, distribute and communicate article's contents, provided the author's and Journal of Industrial Engineering and Management's names are included. It must not be used for commercial purposes. To see the complete license contents, please visit https://creativecommons.org/licenses/by-nc/4.0/. 